\title{
Topical zoledronic acid decreases micromotion induced bone resorption in a sheep arthroplasty model
}

\author{
Thomas Jakobsen ${ }^{1,2^{*}}$, Søren Kold ${ }^{1,2}$, Juan Shiguetomi-Medina' ${ }^{1}$, Jorgen Baas ${ }^{1}$, Kjeld Soballe ${ }^{1}$ and Ole Rahbek
}

\begin{abstract}
Background: Initial micromotion of a total hip replacement is associated with aseptic loosening. The use of bisphosphonates could be one way to reduce peri-implant bone resorption induced by micromotion. Bisphosphonates compounds are inhibitors of bone resorption. The aim of this study was to investigate whether local treatment with bisphosphonate would reduce bone resorption and fibrous tissue around an experimental implant subjected to micromotion.

Methods: One micromotion implant were inserted into each medial femoral condyle in ten sheep. During each gait cycle the implant axially piston $0.5 \mathrm{~mm}$. During surgery one of the femoral condyles were locally treated with $0.8 \mathrm{mg}$ zoledronate. The other condyle served as control. Observation period was 12 weeks.

Results: Histological evaluation showed a fibrous capsule around both the control and bisphosphonate implants. Histomorphometrical analysis showed that $97 \%$ of the surface on both control and bisphosphonate implants were covered by fibrous tissue. However, the bisphosphonate was able to preserve bone in a $1 \mathrm{~mm}$ zone around the implants.

Conclusion: This study indicates that local treatment with bisphosphonate cannot prevent the formation of a fibrous capsule around an implant subjected to micromotion, but bisphosphonate is able to reduce resorption of peri-prosthetic bone.
\end{abstract}

Keywords: Bisphosphonate, Osseointegration, Implant, Animal, Arthroplasty

\section{Background}

Initial stable implant fixation is important for long-term survival of total joint replacements [1,2]. Radiostereometrical studies indicate that early migration is a associated with later revision [1-3]. Treatment strategies that optimize initial implant fixation and prevents early implant migration could have the potential to reduce risks of later revision.

Failure of initial implant osseointegration will result in early implant migration and bone resorption [4]. Early implant migration is associated with reduced resistance to withstand implant movement induced by external load [5]. Continues implant migration is associated with

\footnotetext{
* Correspondence: Thomas.Jakobsen@ki.au.dk

'Orthopaedic Research Laboratory, Department of Orthopaedics, Aarhus

University Hospital, Norrebrogade 44, Building 1A, DK-8000 Aarhus, Denmark

${ }^{2}$ Department of Orthopaedics, Aalborg University Hospital, Aalborg, Denmark
}

implant failure [3]. Early bone resorption can be initiated by an unstable implant generating micro-movement or fluid pressure [6-8]. We have previously shown that implant micromotion without the presence of wear debris can generate a fibrous membrane and cause bone resorption [9]. In vivo studies suggest that instability induced bone resorption works through similar molecular mechanisms as particle induced bone resorption [10, 11]. Aseptic loosening of an implant involves several steps. One of the first steps could be bone resorption due to micro-movement of the implant. The resorption bone is replaced with fibrous tissue. Wear debris will subsequently migrate from the joint articulation along the fibrous tissue to the bone to implant interface and aggravate the process [12, 13]. Longevity of the implant might potentially be increased if micro- 
movement of the implant were not allowed to induce bone resorption.

One way to reduce micromotion induced bone resorption and fibrous membrane formation could be with the use of bisphosphonates. These compounds binds strongly to bone, inhibit osteoclastic activity, and reduce bone resorption [14]. Systemic bisphosphonate treatment has previously in an experimental model of osteolysis been able to reduce bone resorption [15]. We have previously shown that local treatment with bisphosphonate can increase new bone formation, preserve lamellar bone and allograft, and increase biomechanical implant fixation in an experimental joint replacement model [9]. In a clinical study, local treatment with bisphosphonate was shown to reduce acetabular component migration measured by radiostereometrical analysis [16]. The same effect has been observed in the study investigating local ibandronate treatment in total knee arthroplasties [17]. Others have shown the local or systemic treatment with bisphosphonates can reduce but not prevent osteolytic bone resorption and formation of fibrous tissue in a rat model of prosthetic loosening $[18,19]$. Our group has previously shown in a large animal model that systemic alendronate can reduce bone resorption around unstable implants but not prevent it [20]. A stronger stimulus might be needed. Only way to obtain a stronger stimulus could be with topical administration of a third generation bisphosphonate. The aim of this study was to investigate in a sheep arthroplasty model whether topical treatment with bisphosphonate would reduce bone resorption and fibrous tissue.

We tested the hypothesis that local zoledronate treatment would reduce bone resorption and fibrous tissue formation around implants subjected to micromotion.

\section{Methods}

\section{Study design}

We used 10 skeletally mature Danish Landrace sheep with a mean weight of $40 \mathrm{~kg}$ (range, 35-50 kg). The sheep were obtained though our Institutional farm (Påskehøjgaardcentret, 8380 Trige, Denmark) affiliated with our Research facility. Our Institutional Animal Care and Use Committee approved the study. Institutional guidelines for the treatment and care of experimental animals were followed.

In this study, we used a paired design with intervention and control group in the same sheep. We have previously shown that the used model of micromotion is able to induce bone resorption [9]. In each sheep, we inserted one loaded micromotion device (Fig. 1) into each of the medial femoral condyles. Zoledronate was administered locally in one of the knees. Saline was used as control in the contralateral knee. The zoledronate and control implants were systematically alternated between left and right knee. Our observation period was 12 weeks.
Our sample size calculation was based on a previous study [9]. We assumed the standard deviation of the relative change to be $50 \%$. Two-sided $\alpha$ and $\beta$ were set to $5 \%$ and $20 \%$, respectively. We added two extra animals to the calculated sample size of eight to counteract if implants from one or two animals were lost for subsequent analysis.

\section{Implants}

We used 20 custom-made micromotion implant devices (Fig. 1). Our micromotion device has previously been described in detail $[9,21]$. In short, the micromotion device allows a polymethylmethacrylate (PMMA) implant to piston $0.5 \mathrm{~mm}$ with respect to the bone during each step the animal takes. The micromotion creates shear forces in the bone to implant interface. The implants in this study were made sterile by gamma irradiation (2550 kGy for 16 h, Codan Steritex, Espergaerde, Denmark).

\section{Surgery}

With the sheep under general anesthesia, we used our standard anteromedial surgical approach to the knee $[9,21,22]$. Our micromotion device was inserted into the weight-bearing portion of the medial femoral condyle. The procedure has been described in detail in our previously study [9]. During each surgery, we tested and assured that the micromotion device would piston during each gait cycle.

Before the PMMA implant was mounted onto the anchor screw, we soaked the bone cavity for $60 \mathrm{~s}$ with either saline as control or $1 \mathrm{~mL}$ saline containing $0.8 \mathrm{mg}$ zoledronate (Aclasta, Novartis Healthcare A/S, Copenhagen, Denmark) as intervention. After soaking the bone for $60 \mathrm{~s}$, the cavity was rinsed with saline and excess zoledronate or saline together with blood coming from the marrow cavity was sucked away. In this study, all sheep were weight bearing on the operated leg within 5 days of surgery. After the 12 weeks observation period the sheep were euthanized with an overdose of hypersaturated barbiturate and the bones were collected for preparation and analyses. At harvest, all pistons were movable.

\section{Specimen preparation}

Bone specimens were stored at $-20{ }^{\circ} \mathrm{C}$ immediately. We cut each specimen perpendicular to the long axis of the implant using a water-cooled bad saw (Exact Apparatebau, Nordenstedt, Germany) (Fig. 2). The specimens was fixed in $70 \%$ ethanol and used for later analysis. Preparation and subsequent evaluation were blinded.

\section{Histology and Histomorphometry}

All bone-implant specimen were dehydrated in ethanol (70\%-96\%) containing basic fuchsin, and embedded in Epoxy (EPOFIX, Struers, Copenhagen, Denmark). Four 


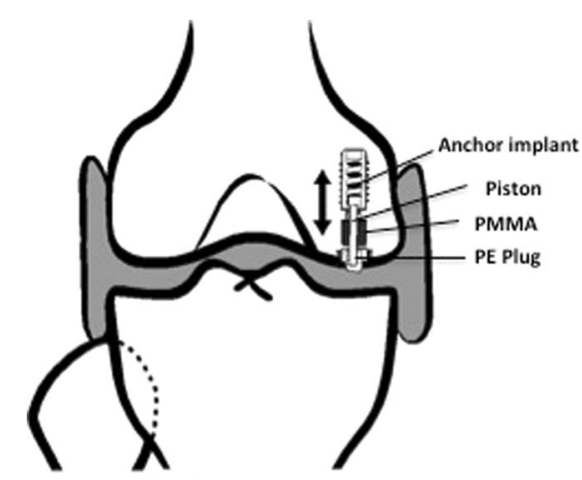

Zoledronate

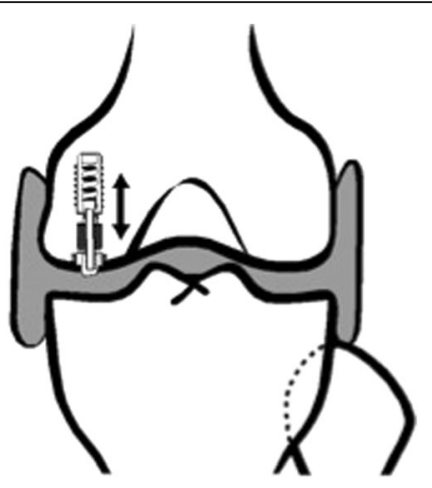

Control

Fig. 1 Schematic drawing showing implant position in the medial femoral condyle. Reproduced with permission from copyright holder/author

$25-\mu \mathrm{m}$ thick sections were cut with a hard tissue microtome (KDG-95, MeProTech, Heerhugowaard, The Netherlands) around the center part of each implant [23]. The sections were cut with a distance of $400 \mu \mathrm{m}$. Before making the sections, the implant was randomly rotated around its long axis. The sections were cut parallel to this axis. These techniques provide reliable results with negligible bias [24]. Before the sections were mounted on glass, we surface stained them with $2 \%$ light-green (BDH Laboratory Supplies, Poole, England).

We used a stereological software program (newCAST, Visiopharm A/S, Horsholm, Denmark) for the histomorphometrical analysis. Volume fractions of bone were estimated by point counting [25] in a zone from the implant surface and $1 \mathrm{~mm}$ into the surrounding bone. Fractions of bone in contact with the implant surface were estimated using sine-weighted lines [26].

\section{Statistical analysis}

Intercooled Stata 9.0 (Stata Inc., College Station, TX, USA) were used for statistical analysis. Statistical analyses were done on ratios between paired data, which were not normally distributed. All variables were log- transformed and Student's paired t-test was performed on absolute differences between normally distributed log-transformed paired data. An absolute difference between the logarithms of a pair of data equals the logarithm of the ratio within the pair [27].

\section{Results}

\section{Surgery}

One sheep died during surgery and was excluded. The remaining 9 sheep completed the 12-weeks observation period. No clinical signs of infection were present at time of euthanization.

\section{Histology}

The most striking difference between the control and zoledronate implants was the presence of a $200-300 \mu \mathrm{m}$ thick fibrous membrane around the control implants (Fig. 3). A fibrous membrane was also present around the zoledronate implants, but the membrane was thinner with an approximately thickness of $50 \mu \mathrm{m}$. The fibrous membrane in both the control and zoledronate group consisted of dense paralleled fibers. No qualitative morphological difference was found between the two groups

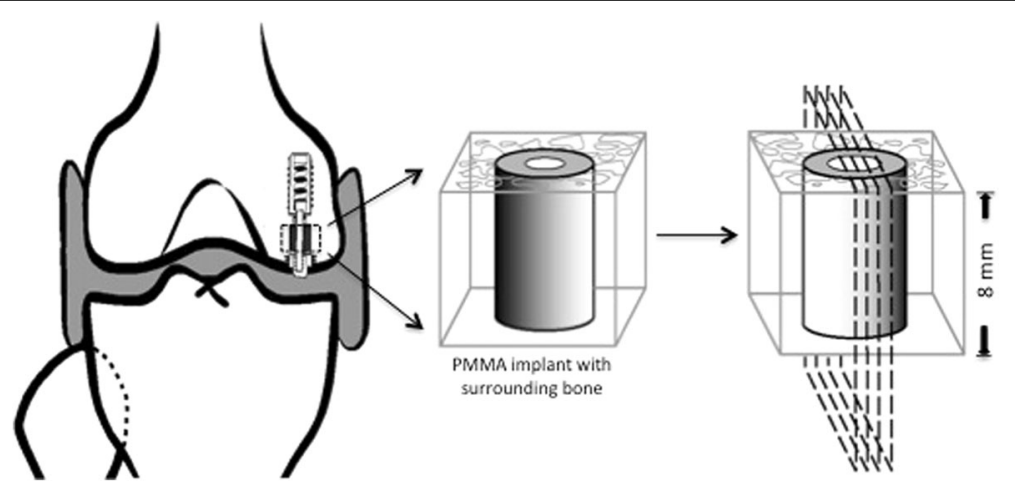

Fig. 2 Schematic diagram showing the specimen preparation. Each bone-implant specimen is embedded and cut into four slides for histomorphometrical analysis. Reproduced with permission from copyright holder/author 

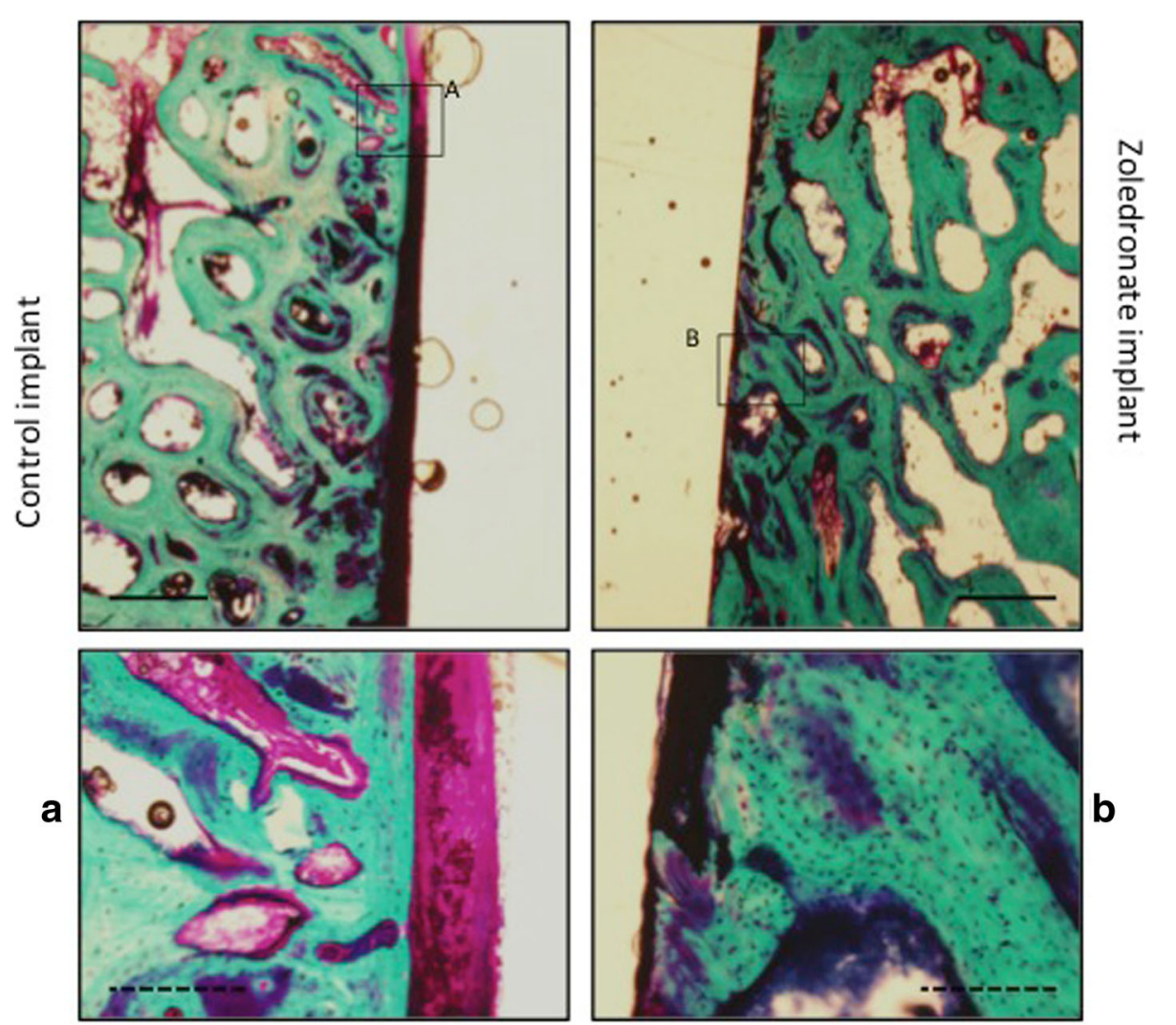

Fig. 3 Representative photomicrographs of samples from the same animal. The samples were stained with basic fuchsin and counterstained with $2 \%$ light green. Note the thick fibrous membrane around the control implant compared to the zoledronate implant. Solid bar $=1 \mathrm{~mm}$. Dotted bar $=0.3 \mathrm{~mm}$

when looking at the bone in the peri-implant zone. The bone consisted mainly of lamellae with spindle-shaped osteocytes in between. Sparse amount of osteoclasts were observed in both groups. No retained bone debris was observed in any of the groups.

\section{Histomorphometrical analysis}

The local zoledronate treatment preserved $14 \%(p=0.02)$ more total bone around the implants in a $1 \mathrm{~mm}$ zone in the zoledronate group compared to the control group (Fig. 4). We found a total peri-implant bone volume fraction of $57 \%$ (95\% CI: $46 \%-67 \%)$ in the control group and $66 \%(95 \% \mathrm{CI}: 53 \%-78 \%)$ in the zoledronate group. No statistically significant changes were found when comparing bone volume fractions for woven $(p=0.08)$ or lamellar $(p=0.32)$ bone (Fig. 3). In the zoledronate group, 16\% (95\% CI: 2\% $29 \%$ ) of $1 \mathrm{~mm}$ peri-implant zone was made of fibrous tissue compared to $23 \%$ (95\% CI: $14 \%-33 \%$ ) in the control group $(p=0.22)$.

The implant surfaces in the both the zoledronate and control group were virtually covered by fibrous tissue. The surface fraction for fibrous tissue was 97\% (95\% CI: $94 \%-100 \%$ ) in the zoledronate group compared to $97 \%$
(95\% CI: $94 \%-99 \%)$ in the control group ( $p=0.65)$. We found no significant differences in the surface-fractions of woven, lamellar, and total bone $(p=0.76, p=0.42$, $p=0.71)$.

\section{Discussion}

The purpose of this study was to investigate whether topical treatment with zoledronate could prevent bone resorption and fibrous tissue formation in our large animal model of micromotion induced bone resorption. We found that zoledronate did not prevent formation of a fibrous membrane, but was able to reduce bone resorption and thickness of the fibrous membrane.

The used model is intended to imitate the bone to cement interface of a total hip replacement. We have previously demonstrated that our experimental model are able to induce peri-implant bone resorption and therefore also suitable to test local adjuvant therapies against bone resorption [9]. The paired design allowed us to eliminate the biological difference between individuals.

Our study is limited by an observation period of 12 weeks and only nine animals completed the study. 


\section{Fraction of bone around implant}

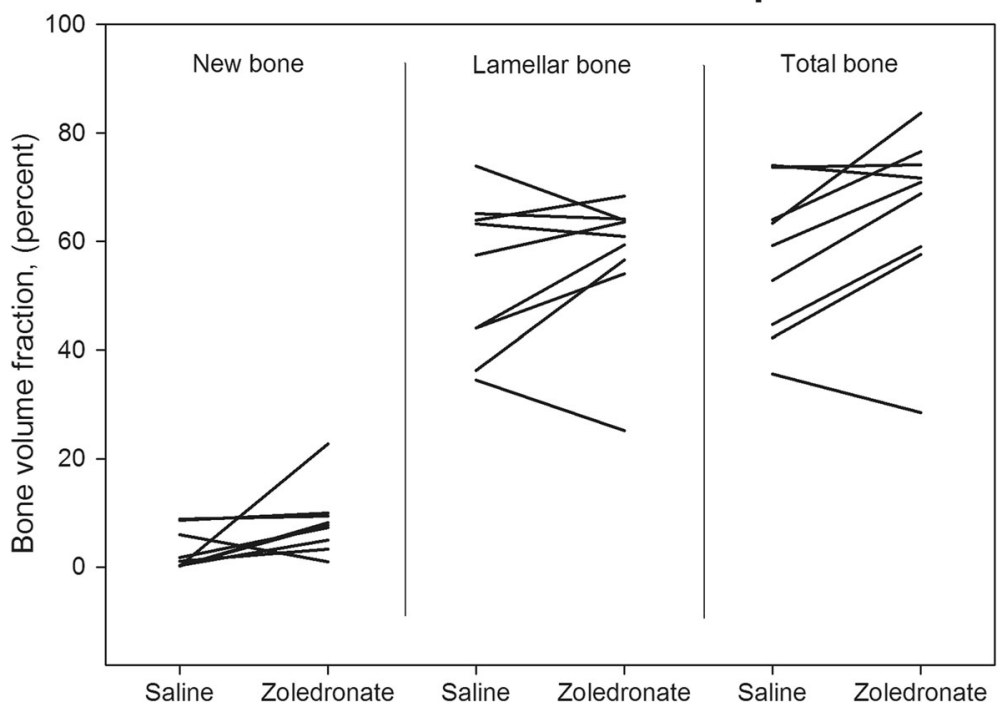

Fig. 4 Tissue-volume fractions in a 0-1 $\mathrm{mm}$ zone around implants. Paired data connected by line

Non-significant differences should therefore be interpreted with caution.

Zoledronate is a potent inhibitor of bone resorption [28]. We have previously shown that local treatment with zoledronate can inhibit resorption of allograft and increase fixation of both primary and revision implants $[29,30]$. In this study, we show that local treatment with zoledronate can reduce resorption of bone in a $1 \mathrm{~mm}$ peri-implant zone around an implant subjected to controlled micromotion.

Our model of micromotion has a piston that allows a $0.5 \mathrm{~mm}$ movement of the implant during each loading. The model was designed to imitate a cemented femoral implant subjected to micromotion. The amplitude of movement of our implant is above the accepted threshold of $0.15 \mathrm{~mm}$ studies and suggested by Van der Voort based on RSA and thereby comparable to clinical implants with a high risk of as aseptic loosening [31]. Furthermore, the loading conditions of both clinical femoral implants and our experimental implants are comparable; both implants transfers load by shear forces though the bone-cement imterface. In our model, movement will occur at the implant-to-bone interface during each gait cycle and thereby create high shear forces and strain between the implant and tissue in contact with the implant. According to studies by and Carter and Giori, the amplitude of strain dictates which tissue can be formed $[32,33]$. A high strain will induce bone resorption and formation of fibrous tissue. We found that local zoledronate treatment were able to partly counteract the strain/micromotion induced bone resorption and preserve $14 \%$ more total bone compared to our control.
An interesting histological finding is the difference in thickness of the fibrous membrane between the zoledronate and control groups. We know from previous studies from our group that micromotion is able to induce formation of a fibrous membrane $[9,34]$. In this study we observed that local zoledronate treatment histologically reduced the thickness of the membrane. It could be that shear forces and stain at the tissue-to-implant interface are to high to by counteracted by zoledronate. Further away form the implant surface, strain and shear forces diminishes and zoledronate are able to partly preserve bone. We know from previous studies that increased amount of bone and decreased amount of fibrous tissue in correlated to increased implant stability [22]. The difference in fibrous layer thickness should therefore have the potential to make the zoledronate implants more mechanically stable.

It has previously been shown that systemic alendronate is able to inhibit bone resorption in a canine osteolytic hip arthroplasty model [15]. An animal study using a rodent model has shown that systemic treatment with alendronate or clodronate can reduce instability-induced bone resorption, but high doses are needed [19]. One likely explanation for the preserved bone volume density found in this study is the inhibitory effect of zoledronate on bone resorption. Previous studies have shown that preservation of lamellar bone often leads to increased formation of new bone [35-37]. The increased new bone formation is explained by increased osteoconductive properties of the preserved lamellar bone. In this study, we are not able to show a statistically significant increase in peri-implant formation of new bone $(8 \%$ in 
zoledronate group vs. $3 \%$ in control group, $p=0.08$ ). One possible explanation could be a to short observation period for new bone formation to occur. The effect on bone formation and resorption has been shown to be different over time [37]. A longer observation period might have shown a more pronounced effect of zoledronate on both bone formation and resorption.

Local treatment with zoledronate was not able to prevent formation of peri-implant fibrous tissue. However, zoledronate was able to reduce the thickness of the periimplant fibrous membrane. This is in agreement with results from another study where local alendronate treatment reduced formation of soft tissue, but did not prevent its formation [19]. It is also in agreement with a clinical study were local ibandronate treatment reduced occurrences of radiolucent lines around acetabular cups lines, but not prevented them [16]. Based on our previous study were systemic alendronate reduced bone resorption around an unstable implant, we expected that a stronger anti-resorptive stimulus could be obtained with local zoledronate. We therefore expected that local zoledronate could prevent bone resorption and formation of fibrous tissue. It may be that implant micromotion is a too strong stimulus for even local zoledronate being able to completely prevent bone resorption. Another explanation could be that the single dose of zoledronate acts only as a defense again bone-resorption for a limited amount of time. Zoledronate, released from bone by osteoclastic resorption, could be slowly washed away from the implant-bone interface. By time the concentration will be too low to inhibit the continuous strong bone resorptive stimulus from micromotion.

In clinical practice, soaking the bone bed before implantation is a simple procedure. We know from a previous studies that the effect on implant osseointegration of local bisphosphonate is dose-dependent $[29,38]$. Bisphosphonate bound to bone will only exert its effect on the osteoclast during bone resorption and intracellular internalization [39]. However, any cell, including bone-forming cells, can internalize unbound bisphosphonate. Removal of unbound bisphosphonate by irrigating the bone bed after soaking it with bisphosphonate is therefore of importance.

\section{Conclusion}

In conclusion, this study indicates that local treatment with zoledronate can reduce micromotion induced bone resorption, but not prevent it. Studies investigating the effect of different zoledronate doses and observation periods are needed.

\section{Abbreviations}

PE: polyethylene; PMMA: polymethylmethacrylate; RSA: Radiostereometric Analysis

\section{Acknowledgements}

The authors wish to thank Jane Pauli, Orthopaedic research Laboratory, Aarhus University Hospital, for technical expertise. The authors declare to have no professional or financial conflict of interest.

\section{Authors'contributions \\ TJ, SK, JB, KS, and OR: Designed the study. TJ, SK, JB, and OR: performed the surgery. TJ and JSM: specimen preparation and histomorphometry. TJ, and JB: push-out test. TJ: Statistical analysis. TJ, SK, JSM, JB, KS, and OR: Interpretation of data. TJ wrote the first draft of the manuscript. SK, JSM, JB, KS, and OR: critically revision of manuscript. All authors read and approved the final manuscript.}

\section{Funding}

This study was unconditionally funded by The Danish Ministry of Higher Education and Science.

\section{Availability of data and materials \\ The datasets used and/or analysed during the current study are available from the corresponding author on reasonable request.}

\section{Ethics approval and consent to participate}

The study was approved by our Institutional Animal Care and Use Committee affiliated with the Danish Ministry of Environment and Food (2006/561-1201).

Consent for publication

Not applicable.

\section{Competing interests}

The authors declare that they have no competing interests.

\section{Publisher's Note}

Springer Nature remains neutral with regard to jurisdictional claims in published maps and institutional affiliations.

Received: 28 June 2017 Accepted: 3 November 2017

Published online: 13 November 2017

\section{References}

1. Kärrholm J, Borssén B, Löwenhielm G, Snorrason F. Does early micromotion matter? 4-7 year stereoradiographic follow-up of 84 cemented prostheses. J Bone Jt Surg - Br Vol. 1994;76:912-7.

2. Ryd L, Albrektsson E, Carlsson L, Dansgaard F, Herberts $P$, Regnér $L$, et al. Roentgen of knee of mechanical analysis loosening as a predictor continues. J Bone Jt Surg - Br Vol. 1995;77:377-83.

3. Nieuwenhuijse MJ, Valstar ER, Kaptein BL, Nelissen RGHH. Good diagnostic performance of early migration as a predictor of late aseptic loosening of acetabular cups: results from ten years of follow-up with Roentgen stereophotogrammetric analysis (RSA). J Bone Joint Surg Am. 2012;94:874-80

4. Ollivere B, Wimhurst JA, Clark IM, Donell ST. Current concepts in osteolysis. J Bone Joint Surg Br. 2012;94:10-5.

5. Hilding MB, Yuan $X$, Ryd L. The stability of three different cementless tibial components. A randomized radiostereometric study in 45 knee arthroplasty patients. Acta Orthop Scand. 1995;66:21-7.

6. Aspenberg P, Herbertsson P. Periprosthetic bone resorption. J Bone Jt Surg Br. 1996;78:641-6.

7. Skripitz R, Aspenberg P. Pressure-induced periprosthetic osteolysis: a rat model. J Orthop Res. 2000;18:481-4.

8. Aspenberg P, Van der Vis H. Migration, particles, and fluid pressure. A discussion of causes of prosthetic loosening. Clin Orthop Relat Res. 1998:75-80

9. Jakobsen T, Kold S, Baas J, Søballe K, Rahbek O. Sheep hip Arthroplasty model of failed implant Osseointegration. Open Orthop J. 2015;9:525-9.

10. Amirhosseini $M$, Andersson $G$, Aspenberg $P$, Fahlgren A. Mechanical instability and titanium particles induce similar transcriptomic changes in a rat model for periprosthetic osteolysis and aseptic loosening. Bone Reports. 2017;7:17-25.

11. Amirhosseini M, Madsen RV, Escott KJ, Bostrom M, Ross FP, Fahlgren A. GSK$3 \beta$ inhibition suppresses instability-induced Osteolysis by a dual action on osteoblast and osteoclast differentiation. J Cell Physiol. 2017; 
12. Goodman S, Gibon E, Yao Z. The basic science of Periprosthetic Osteolysis. Instr Course Lect. 2001:201-6.

13. Jacobs JJ, Roebuck KA, Archibeck M, Hallab NJ, Glant TT. Osteolysis: basic science. Clin Orthop Relat Res 2001:71-77.

14. Fleisch H. Development of bisphosphonates. Breast Cancer Res. 2002;4:30-4.

15. Shanbhag AS, Hasselman CT, Rubash HE. The John Charnley award. Inhibition of wear debris mediated osteolysis in a canine total hip arthroplasty model. Clin Orthop Relat Res. 1997:33-43.

16. Schilcher J, Palm L, Ivarsson I, Aspenberg P. Local bisphosphonate reduces migration and formation of radiolucent lines adjacent to cemented acetabular components. Bone Jt J. 2017;99:317-24.

17. Hilding M, Aspenberg P. Local peroperative treatment with a bisphosphonate improves the fixation of total knee prostheses: a randomized, double-blind radiostereometric study of 50 patients. Acta Orthop. 2007:78:795-9.

18. Astrand J, Skripitz R, Skoglund B, Aspenberg PA. Rat model for testing pharmacologic treatments of pressure-related bone loss. Clin Orthop Relat Res. 2003:296-305

19. Astrand J, Aspenberg P. Reduction of instability-induced bone resorption using bisphosphonates. Acta Orthop. 2002;73:24-30.

20. Søballe K, Chen X, Jensen TB, Kidder L, Bechtold JE. Alendronate treatment in the revision setting, with and without controlled implant motion: an experimental study in dogs. Acta Orthop. 2007;78:800-7.

21. Bechtold JE, Kubic V, Søballe KA. Controlled experimental model of revision implants. Acta Orthop Scand. 2001;72:642-9.

22. Jakobsen T, Kold S, Bechtold JE, Elmengaard B, Søballe K. Effect of topical alendronate treatment on fixation of implants inserted with bone compaction. Clin Orthop Relat Res. 2006;444:229-34.

23. Overgaard S, Søballe K, Jørgen H, Gundersen G. Efficiency of systematic sampling in histomorphometric bone research illustrated by hydroxyapatitecoated implants: optimizing the stereological vertical-section design. J Orthop Res. 2000;18:313-21.

24. Baas J. Adjuvant therapies of bone graft around non-cemented experimental orthopaedic implants. Acta Orthop. 2008;79:2-43.

25. Gundersen HJ, Bagger P, Bendtsen TF, Evans SM, Korbo L, Marcussen N, et al. The new stereological tools: disector, fractionator, nucleator and point sampled intercepts and their use in pathological research and diagnosis. APMIS. 1988:96:857-81.

26. Baddeley AJ, Gundersen HJ, Cruz-Orive LM. Estimation of surface area from vertical sections. J Microsc. 1986;142:259-76.

27. Bland JM, Altman DG. Statistics notes: the use of transformation when comparing two means. BMJ 1996;312:1153-1153.

28. Gatti D, Adami S. New bisphosphonates in the treatment of bone diseases. Drugs Aging. 1999;15:285-96.

29. Jakobsen T, Baas J, Bechtold JE, Elmengaard B, Søballe K. The effect of soaking allograft in bisphosphonate: a pilot dose-response study. Clin Orthop Relat Res. 2010;468:867-74.

30. Sørensen M, Barckman J, Bechtold JE, Soballe K, Baas J. Preclinical evaluation of Zoledronate to maintain bone allograft and improve implant fixation in. J Bone Jt Surg - Am Vol. 2013:1862-8.

31. van der Voort P, Pijls BG, Nieuwenhuijse MJ, Jasper J, Fiocco M, Plevier JWM et al. Early subsidence of shape-closed hip arthroplasty stems is associated with late revision. A systematic review and meta-analysis of 24 RSA studies and 56 survival studies. Acta Orthop. 2015;86:575-85.

32. Giori NJ, Ryd L, Carter DR. Mechanical influences on tissue differentiation at bone-cement interfaces. J Arthroplast. 1995;10:514-22.

33. Carter DR, Fyhrie DP, Whalen RT. Trabecular bone density and loading history: regulation of connective tissue biology by mechanical energy. J Biomech. 1987;20:785-94

34. Bechtold JE, Mouzin O, Kidder L, Part II. Implementation with loaded titanium implants and bone graft. Acta Orthop Scand. 2001;72:650-6.

35. Baas J, Elmengaard B, Jensen TB, Jakobsen T, Andersen NT, Soballe K. The effect of pretreating morselized allograft bone with rhBMP-2 and/or pamidronate on the fixation of porous Ti and HA-coated implants. Biomaterials. 2008;29:2915-22.

36. Jakobsen T, Kold S, Bechtold JE, Elmengaard B, Søballe K. Local alendronate increases fixation of implants inserted with bone compaction: 12-week canine study. J Orthop Res. 2007;25:432-41.

37. Kettenberger U, Ston J, Thein E, Procter P, Pioletti DP. Does locally delivered Zoledronate influence peri-implant bone formation? - Spatio-temporal monitoring of bone remodeling in vivo. Biomaterials. 2014;35:9995-10006.
38. Jakobsen T, Baas J, Bechtold JE, Elmengaard B, Søballe K. Soaking morselized allograft in bisphosphonate can impair implant fixation. Clin Orthop Relat Res. 2007;463:195-201.

39. Russell RGG. Bisphosphonates: mode of action and pharmacology. Pediatrics. 2007;119(Suppl):S150-62.

\section{Submit your next manuscript to BioMed Central and we will help you at every step:}

- We accept pre-submission inquiries

- Our selector tool helps you to find the most relevant journal

- We provide round the clock customer support

- Convenient online submission

- Thorough peer review

- Inclusion in PubMed and all major indexing services

- Maximum visibility for your research

Submit your manuscript at www.biomedcentral.com/submit
Biomed Central 